\title{
Effect of Population Density on Timing of Oviposition and Brood Size Reduction in the Burying Beetle Nicrophorus pustulatus Herschel (Coleoptera: Silphidae)
}

\author{
Claudia M. Rauter and Renae L. Rust \\ Department of Biology, University of Nebraska at Omaha, Allwine Hall 114, 6001 Dodge Street, Omaha, NE 68182-0040, USA \\ Correspondence should be addressed to Claudia M. Rauter, crauter@unomaha.edu
}

Received 2 October 2011; Revised 3 January 2012; Accepted 5 January 2012

Academic Editor: Brian Forschler

Copyright ( $) 2012$ C. M. Rauter and R. L. Rust. This is an open access article distributed under the Creative Commons Attribution License, which permits unrestricted use, distribution, and reproduction in any medium, provided the original work is properly cited.

\begin{abstract}
Burying beetles (Nicrophorus spp.) bury small carcasses to feed their larvae. Carcasses are a limited, high-quality resource and contests over carcasses become more frequent with increasing population density. Successful beetles kill eggs and larvae present on carcass. In response, females should accelerate oviposition, while offspring development should increase to minimize mortality. Both value of a carcass and frequency of contests decrease as larvae develop. If overproduction of offspring is an insurance against high mortality, females should reduce brood size as carcass value declines. Testing our predictions, we reared female burying beetles, Nicrophorus pustulatus, at high and low densities and compared oviposition and brood reduction. High-density females delayed oviposition, suggesting that high population density imposes nutritional and/or physiological stress. Females responded to the physiological constraints and the potentially high mortality rates of eggs and newly hatched larvae by lengthening oviposition period and changing brood reduction rate.
\end{abstract}

\section{Introduction}

In response to environmental conditions, females can adjust their reproductive phenotype by modifying the number and size of offspring [1-6]. As population density increases, females often produce fewer and larger offspring [1, 38]. This is commonly observed when females compete for access to resources, and increased population density leads to more frequent and intense contests over these resources $[1,3,6]$. Adjustment of offspring number and, to a smaller degree, adjustment of offspring size, can occur during every stage of reproduction [9-11]. Females can regulate the number and size of eggs they produce $[2,12]$ and actively destroy eggs [11]. In animals with extensive parental care, reduction of offspring number can also occur after hatching or birth of offspring $[9,10]$. Typically, females cause the death of an offspring indirectly by feeding the most competitive offspring preferentially and/or ignoring aggressive fatal interactions among competing siblings [10].
In some species, filial infanticide has been observed as the means of brood reduction $[9,10]$.

Burying beetles (Nicrophorus spp.) provide extensive parental care and are known to adjust brood size primarily through filial infanticide [13-15]. Burying beetles use small dead vertebrates (e.g., mice and birds) as food resource for their offspring. Severe contests over the ephemeral resources are usually won by the larger beetles. A carcass, once discovered by a pair of burying beetles or a single female, is quickly buried. While burying the carcass, the beetles remove fur or feathers, deposit oral and anal secretions, and work the carcass into a ball. Within 12 to $48 \mathrm{~h}$ after discovery of the carcass, the female lays eggs in the soil surrounding the carcass [13-15]. Clutch size is substantially larger than the number of larvae dispersing [14]. Females lay larger clutches when carcass size increases [16]. After the larvae have hatched, they crawl to the carcass where they are fed by the parents with regurgitated carcass for about three days. Afterwards, the larvae feed by themselves. The male generally 
deserts the brood when the larvae are feeding by themselves, while the female stays with the larvae until the larvae have consumed the carcass and are dispersing to pupate in the soil [13-15].

Despite being buried, the carcass can still be discovered by other burying beetles $[14,15,17]$. Successful intruders kill all eggs and larvae encountered [18]. Takeovers occur most frequently between burial of the carcass and hatching of the larvae [19]. Thereafter, takeovers quickly become less likely because the resource value of the carcass decreases as it is consumed, and levels off at very low values when the larvae are about two-to three-days old. [18]. Assuming that overproduction of eggs is an insurance against high mortality rates of eggs and newly hatched larvae [20], we predict that female burying beetles will start adjusting brood size through infanticide after the larvae started hatching and both the value of the carcass and the likelihood of takeovers are declining rapidly, and finish adjusting brood size when the two- to three-day-old larvae have reduced the value of the carcass for other burying beetles. Changes in population density may influence the temporal pattern of offspring number reduction. With higher population density, we expect that intrusions become more likely and with it the possibility of partial infanticide in a failed take-over attempt. To be able to compensate potential loss of eggs and larvae, high-density females should therefore wait longer to reduce their broods.

Based on life history theory [21], we assume that a high probability of takeovers exerts strong selection on minimizing the duration of the developmental stage(s) with very high offspring mortality rates. At high population density, females should thus accelerate oviposition as well as egg and larval development, which can be influenced by females though transmission of nongenetic developmental resources $[22,23]$. Consequently, larvae would hatch earlier and develop faster, thus consuming the carcass sooner causing a steeper decline in the value of the carcass. The final brood size of high-density females, however, should be lower than that of low-density females. To maximize fitness, females experiencing high population density with frequent contests over resources won by large individuals, should produce fewer, but larger, offspring than low-density females [24].

To test our hypotheses, we reared female $N$. pustulatus at high- and low densities and compared timing of oviposition and brood reduction as well as offspring development and size between high- and low-density females. In particular, we addressed the following questions: (1) do high-density females lay eggs earlier than low-density females?, (2) do eggs and larvae of high-density females develop more rapidly?, (3) do high-density females adjust brood size later than lowdensity females, and (4) will they have fewer, but larger, larvae dispersing?

\section{Material and Methods}

Burying beetles N. pustulatus used in this study, came from a laboratory colony established in 2002 with 92 pairs of beetles caught in the Research Forest of Berea College, KY, USA.
The beetles of this laboratory colony are kept individually in containers $(15 \mathrm{~cm} \times 10 \mathrm{~cm} \times 5 \mathrm{~cm})$ filled $2 \mathrm{~cm}$ deep with humid peat at a 15L:9D photoperiod and $22 \pm 1^{\circ} \mathrm{C}$. The beetles are fed a pea-sized amount of canned cat food (Science Diet, Hill's Pet Nutrition Inc., Topeka, KS, USA) twice weekly.

This study was carried out in summer 2006. To investigate the effect of population density on timing of oviposition, offspring development, and brood size reduction as well as offspring size, we assigned newly emerged females from the laboratory colony at random to a high-density (i.e., four females per container) or a low-density treatment (i.e., one female per container $)$. Container size $(15 \mathrm{~cm} \times 10 \mathrm{~cm} \times 5 \mathrm{~cm})$ was the same for both treatments. All containers were filled $2 \mathrm{~cm}$ deep with moist peat. Twice weekly, we placed a peasized amount of canned cat food (Science Diet, Hill's Pet Nutrition Inc., Topeka, KS, USA) in all containers with lowdensity females, while containers with high-density females received four times the amount of canned cat food.

When the females were between 28 and 58 days old and sexually mature, the females were assigned at random to offspring developmental stages at which the trial would be terminated. At termination, offspring number and size as well as time elapsed to reach the particular developmental stage were determined. The offspring developmental stages included: $E_{1.5}$ (first laid eggs were 1.5 days old), $L_{0.5}, L_{1}$, $L_{1.5}, L_{2}, L_{2.5}, L_{3}$ (oldest larvae were $0.5,1,1.5,2,2.5$, or 3 days old), and $L_{\text {dispersal }}$ (larvae had left the brood cavity and were dispersing). Females assigned to the different offspring developmental stages and density treatments did not differ in age (developmental stage of offspring: $F_{7,281}=$ 1.84, $P=0.08$; female density treatment: $F_{1,281}=2.40$, $P=0.12)$. Once assigned to an offspring developmental stage, females were transferred to a new container $(15 \mathrm{~cm} \times$ $10 \mathrm{~cm} \times 5 \mathrm{~cm}$ ) filled $2 \mathrm{~cm}$ deep with moist peat and mated with a randomly chosen, nonsibling male from the colony. A total of 320 matings were set up: 20 matings for each combination of female density and offspring developmental stage. The following day, the male was removed, and a previously frozen mouse (mean \pm SD: $23.7 \pm 2.0$ g; range: 18.0 to $27.9 \mathrm{~g}$ ) was placed into the container with the female. Average mouse weight did not differ between high- and lowdensity females $\left(F_{1,281}=0.18, P=0.67\right)$ and between the different developmental stages $\left(F_{7,281}=0.38, P=0.91\right)$. To simulate conditions underground, containers with mice were kept in a dark room at $22 \pm 1^{\circ} \mathrm{C}$. Containers were checked twice daily for eggs and newly hatched larvae. When the offspring had reached the designated developmental stage, the container was searched for eggs, and the larvae were removed from the carcass. For all developmental stages, eggs were counted, but egg size was only determined for the stage $E_{1.5}$. From each container of stage $E_{1.5}$, the length of a subsample of 10 eggs was measured using a dissecting scope with an ocular micrometer. The larvae of each container were counted, and the brood weight was measured. Larval weight for each brood was calculated as brood weight divided by the number of larvae. Offspring number for each brood was determined as the sum of all eggs and all larvae found in a container. Time elapsed until oviposition was determined as 
the number of half-days between the time when the mouse was added to the container (i.e., earliest time when females could discover the carcass), and the first observation of eggs in the container. Egg development was defined as number of half-days between the first observation of eggs and the first observation of newly hatched larvae. Larval development was calculated as number of half-days between the first observation of newly hatched larvae and the point in time when larvae were dispersing.

2.1. Statistical Analysis. Time elapsed until oviposition, egg development, and larval development were analyzed with the GENMOD procedure in SAS (SAS Institute Inc., Cary, NC, USA). Poisson distribution and the log function were chosen as error distribution and link function, respectively. Female density was the main effect in the model and mouse weight was included as covariate. Offspring number and number of eggs and larvae were also analyzed with the GENMOD procedure using Poisson distribution and the log function as error distribution and link function, respectively. We included in the models as main factors female density and developmental stage of offspring and the interaction of the two main effects. Mouse weight was used as covariate. Egg length and larval weight were analyzed with the GLM procedure in SAS. The model for egg length included female density as main effect and mouse weight as covariate. The model for larval weight contained as main factors female density and developmental stage of offspring and the interaction of the two main effects. Mouse weight was used as covariate. Larval mass was natural log-transformed before analysis to achieve normality. Not all of the original 340 matings were successful; therefore, only 297 broods were included in the data analyses.

\section{Results}

3.1. Duration of Development. High-density females began to lay eggs later than low-density females $\left(\chi^{2}=6.57\right.$, d.f. $=1$, $N=297, P=0.01$; Figure 1$)$. The duration of egg and larval development did not differ between high- and low-density females (eggs: $\chi^{2}=0.02$, d.f. $=1, N=260$, and $P=0.89$; larvae: $\chi^{2}=0.17$, d.f. $=1, N=40$, and $P=0.68$; Figure 1 ). Mouse weight had neither an effect on the start of oviposition $\left(\chi^{2}=0.05\right.$, d.f. $\left.=1, P=0.83\right)$ nor on the duration of egg or larval development (eggs: $\chi^{2}=0.15$, d.f. $=1$, and $P=0.70$; larvae: $\chi^{2}=0.01$, d.f. $=1$, and $P=0.93$ ).

3.2. Number of Offspring. The total number of offspring was significantly affected by the developmental stage of the offspring ( $\chi^{2}=1778.18$, d.f. $=7, N=297$, and $\left.P<0.0001\right)$. Offspring number was largest at the egg stage and declined continuously until the first-hatched larvae were two days old. From then on, offspring number changed little (Figure 2(a)). Both high-density and low-density females showed the same pattern in the change of offspring number in relation to the developmental stage of the offspring (interaction between density and developmental stage: $\chi^{2}=11.47$, d.f. $=7$, $N=297$, and $P=0.12$ ). However, high-density females

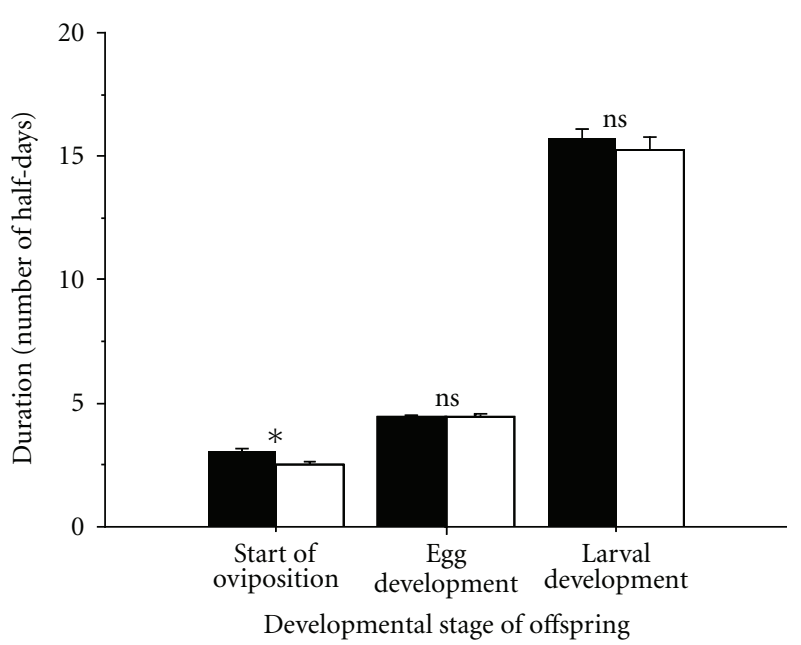

Figure 1: Effect of density on time elapsed until the first egg was laid (i.e., start of oviposition) as well as egg and larval development. Black bars: high-density females; white bars: low-density females. Means and SE are shown. ${ }^{*} P=0.01$; ns: not significant.

had significantly fewer offspring than low-density females $\left(\chi^{2}=10.47\right.$, d.f. $=1, N=297$, and $P=0.001$; Figure $\left.2(\mathrm{a})\right)$. Offspring number increased as mouse weight increased $\left(\chi^{2}=\right.$ 24.15 , d.f. $=1, N=297, P<0.0001$, and slope $=0.03)$.

The number of eggs present after the first larvae had hatched, depended on the developmental stage of the offspring $\left(\chi^{2}=335.70\right.$, d.f. $=3, N=220$, and $P<0.0001$; Figure 2(b)). However, in broods of high-density females, there were more eggs present and for a longer time than in broods of low-density females (Density: $\chi^{2}=7.08$, d.f. $=1$, $N=220$, and $P=0.01$; interaction between density and developmental stage: $\chi^{2}=25.47$, d.f. $=3, N=220$, and $P<0.0001)$. The number of eggs present increased as mouse weight increased ( $\chi^{2}=29.03$, d.f. $=1, N=220, P<0.0001$, and slope $=0.09)$.

The number of larvae present on the carcass after the first larvae had hatched was significantly affected by the age of the larvae $\left(\chi^{2}=354.89\right.$, d.f. $=6, N=260$, and $P<0.0001$; Figure $2(\mathrm{c}))$. The pattern of change in larvae number with larval age differed between high- and low-density females (interaction between density and developmental stage: $\chi^{2}=$ 14.82 , d.f. $=6, N=260$, and $P=0.02$ ). On carcass of lowdensity females, the decline in larvae number began earlier, but leveled off at the same time as the number of larvae on carcass of high-density females (Figure 2(c)). Overall, highdensity females had fewer larvae than low-density females $\left(\chi^{2}=24.46\right.$, d.f. $=1, N=260$, and $\left.P<0.0001\right)$. The number of larvae increased with increasing mouse weight $\left(\chi^{2}=10.37\right.$, d.f. $=1, N=260, P=0.001$, and slope $\left.=0.02\right)$.

3.3. Offspring Size. Egg size (measured as egg length) did not differ between high- and low-density females $\left(F_{1,33}=0.69\right.$ and $P=0.41$; Figure $3(\mathrm{a})$ ). The size of larvae (measured as larval weight) changed significantly with larval age $\left(F_{6,245}=\right.$ 224.45, and $P<0.0001$; Figure 3(b)). But the pattern of the larval weight increase with larval age did not differ between 


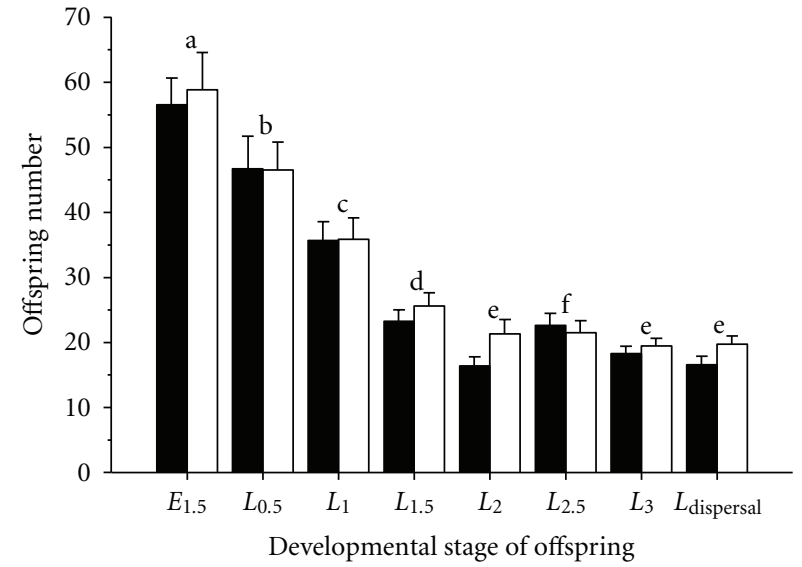

(a)

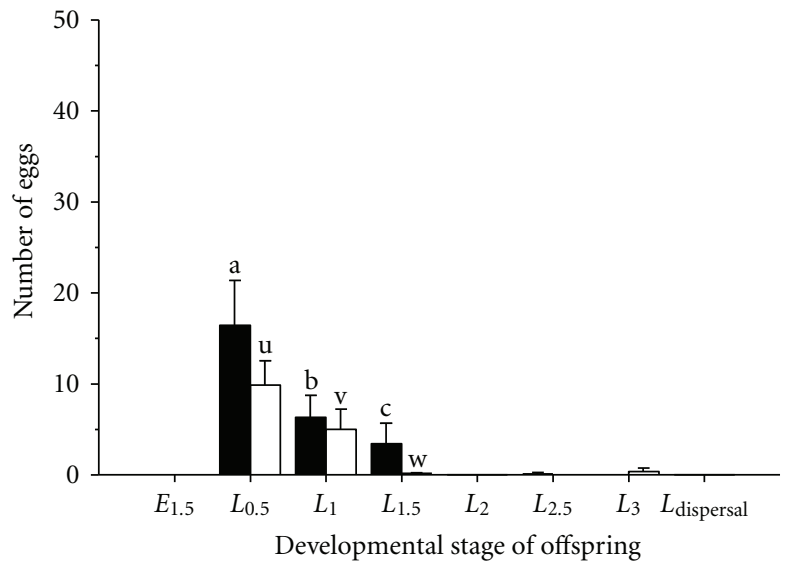

(b)

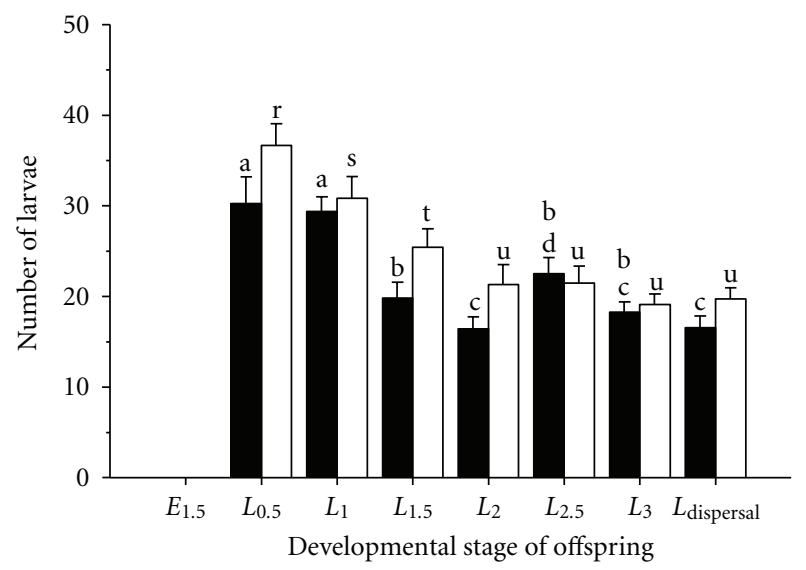

(c)

FIGURE 2: Total number of offspring (a), number of eggs present after first larvae had hatched (b), and number of larvae (c) in relation to developmental stage of offspring for high-density (black bars) and low-density females (white bars). $E_{1.5}$ : first laid eggs were 1.5 days old; $L_{0.5}, L_{1}, L_{1.5}, L_{2}, L_{2.5}$, and $L_{3}$ : oldest larvae were $0.5,1,1.5,2,2.5$, or 3 days old; $L_{\text {dispersal }}$ : larvae had left the brood cavity and were dispersing. Different letters above bars in (a) indicate difference at $P<0.05$ between developmental stages for both female densities combined, while different letters above bars in (b) and (c) indicate difference at $P<0.05$ between developmental stages within each female density treatment. Means and SE are shown.

high- and low-density females (interaction between density and developmental stage: $F_{6,245}=1.96$ and $P=0.07$ ). Larval weight did not differ between high- and low-density females $\left(F_{1,245}=2.98, P=0.09\right)$. Mouse weight affected neither egg size $\left(F_{1,33}<0.01, P=0.95\right)$ nor larval weight $\left(F_{1,245}=0.03\right.$, $P=0.86)$.

\section{Discussion}

As predicted, high-density females had overall fewer offspring (i.e., eggs and larvae) and, in particular, fewer larvae than low-density females, corroborating other studies on burying beetles $[1,6]$. However, contrary to our prediction and Creighton's [1] study on N. orbicollis, offspring of highdensity females were not larger than offspring of low-density females. This may be due to weaker selection on larval mass in N. pustulatus compared to N. orbicollis, as we have suggested previously [6]. Although N. pustulatus accept mice readily for reproduction in the laboratory and show the same behaviors as other burying beetles, a host shift to snake eggs has been observed $[25,26]$. A clutch of snake eggs may provide breeding opportunities for more than one pair of beetles therefore reducing intensity of selection on body size.

Our experiment showed that the number of larvae on carcass of high-density females started to decline later than on carcass of low-density females, even though the number of eggs was declining for both high- and low-density females (Figures 2(b) and 2(c)). This suggests that highdensity females began brood reduction at the same time as low-density females, but differed in the rate of brood reduction. After initiation of brood reduction, high-density females seemed to reduce their broods at a slower rate than low-density females, but soon after reduced their broods much faster (Figure 2(c)). Consequently, both high- and low-density females reached their final brood size when the larvae were two days old (Figure 2(c)). This pattern of brood reduction may be a bet-hedging strategy allowing high-density females, in case a failed takeover with partial 


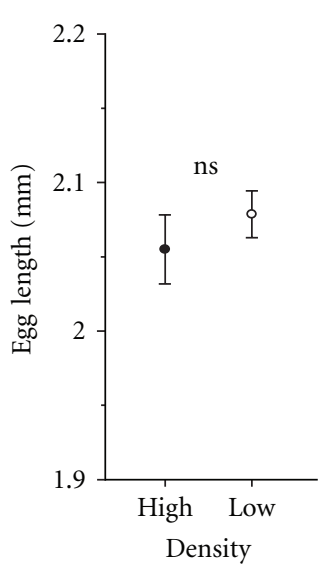

(a)

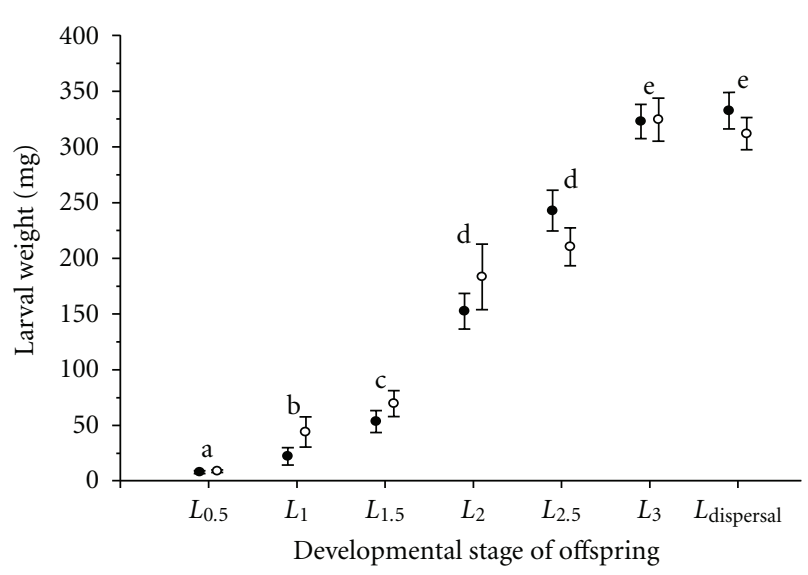

(b)

FIGURE 3: Egg size (measured as egg length) (a) and larval weight in relation to developmental stage of offspring (i.e., larval age) (b) for high (filled circles) and low-density females (open circles). $L_{0.5}, L_{1}, L_{1.5}, L_{2}, L_{2.5}$, and $L_{3}$ : oldest larvae were $0.5,1,1.5,2,2.5$, or 3 days old; $L_{\text {dispersal }}$ : larvae had left the brood cavity and were dispersing. Different letters indicate difference at $P<0.05$ between developmental stages for both female densities combined. Means and SE are shown.

infanticide occurs, to compensate the loss of offspring, while maximizing larval growth. Reducing the number of larvae as fast as possible may be beneficial because a larger brood size early in development can negatively affect the final size of larvae (Chris Effken and Claudia Rauter, unpublished data).

High-density females began to oviposit later and had more eggs and for a longer time than low-density females suggesting that high-density females oviposit not only later, but also over a longer time period and that larvae hatch more asynchronously. This oviposition pattern may have been caused by lower body condition of high-density females. Even though high-density females received the same amount of food per individual, behavioral interactions among highdensity females may have lead to higher energy use and unequal access to food causing nutritional stress and lower body condition. In a similar experiment [6] where we maintained 1,2, 4, or 6 female beetles in a container, we found that body weight of small females within high-density containers, decreased as density increased indicating nutritional stress. In the burying beetle $N$. orbicollis nutritional stress in form of low quality diet leads to slower ovarian development and delayed oviposition as well as to fewer and smaller eggs [27]. An alternative, but not mutually exclusive, physiological explanation for the delayed and extended oviposition by high-density females may be physiological stress in form of elevated stress hormone levels. Competitive interactions among conspecifics can cause physiological stress in form of elevated levels of stress hormones [28-32], which can adversely affect reproduction $[32,33]$.

Later oviposition and a longer oviposition period at high population density, may not only be the consequence of physiological stress, but also be an adaptive response to high population density with increased competition for carcass. Delayed oviposition of high-density females can have fitness benefits, if after an unsuccessful take-over attempt the losing, subdominant female stays close and lays eggs, usually earlier than the successfully defending, dominant female, near the carcass $[34,35]$. Typically, the larvae of the subdominant female hatch earlier and are killed by the dominant female [35]. Larvae present on the carcass, before the female's own larvae are hatching, are killed by the female because burying beetles use temporal cues to distinguish between their own and unrelated larvae $[35,36]$. Eggert and Müller [35] suggested that delayed oviposition by the dominant female in nontolerant breeding associations allows the dominant female to better discriminate between related and unrelated larvae, and preferentially kill unrelated larvae, thus increasing its fitness.

At high-density, an extended oviposition period and thus more asynchronous hatching of larvae may also be an adaptation to unpredictable and variable survival of eggs and newly hatched larvae when the take-over risk is high. Assuming that the value of a carcass decreases with decreasing carcass size similarly to the decrease in value observed in carcasses that are consumed by developing larvae [18], our results show the same patterns as findings in $N$. vespilloides [37]. With increasing carcass size, female $N$. vespilloides lay eggs in larger intervals resulting in more asynchronous hatching of larvae [37].

Our data suggest that high population density imposes nutritional and/or physiological stress on females causing delayed oviposition. However, females respond to the physiological constraints and the potentially high mortality rates of eggs and newly hatched larvae by lengthening the oviposition period and changing the brood reduction rate.

\section{Acknowledgments}

The authors thank Andria Bethelmie and John Harnisch for help with data collection. Mark Schoenbeck and an anonymous reviewer provided helpful comments on earlier versions of the paper. This work was partially funded by NSF STEP Grant no. IBN-0336462. 


\section{References}

[1] J. C. Creighton, "Population density, body size, and phenotypic plasticity of brood size in a burying beetle," Behavioral Ecology, vol. 16, no. 6, pp. 1031-1036, 2005.

[2] S. Eggers, M. Griesser, M. Nystrand, and J. Ekman, "Predation risk induces changes in nest-site selection and clutch size in the Siberian jay," Proceedings of the Royal Society B, vol. 273, no. 1587, pp. 701-706, 2006.

[3] M. Goubault, A. F. S. Mack, and I. C. W. Hardy, "Encountering competitors reduces clutch size and increases offspring size in a parasitoid with female-female fighting," Proceedings of the Royal Society B, vol. 274, no. 1625, pp. 2571-2577, 2007.

[4] T. Tully and R. Ferrière, "Reproductive flexibility: genetic variation, genetic costs and long-term evolution in a collembola," PLoS ONE, vol. 3, no. 9, Article ID e3207, 2008.

[5] J. Leips, J. M. L. Richardson, F. H. Rodd, and J. Travis, "Adaptive maternal adjustments of offspring size in response to conspecific density in two populations of the least killifish, heterandria formosa," Evolution, vol. 63, no. 5, pp. 1341-1347, 2009.

[6] C. M. Rauter, M. J. McGuire, M. M. Gwartney, and J. E. Space, "Effect of population density and female body size on number and size of offspring in a species with size-dependent contests over resources," Ethology, vol. 116, no. 2, pp. 120-128, 2010.

[7] J. Leips and J. Travis, "The comparative expression of lifehistory traits and its relationship to the numerical dynamics of four populations of the least killifish," Journal of Animal Ecology, vol. 68, no. 3, pp. 595-616, 1999.

[8] C. Both, "Density dependence of avian clutch size in resident and migrant species: is there a constraint on the predictability of competitor density?" Journal of Avian Biology, vol. 31, no. 3, pp. 412-417, 2000.

[9] G. Hausfater and S. B. Hrdy, Infanticide: Comparative and Evolutionary Perspectives, Aldine Publishing Company, New York, NY, USA, 1984.

[10] D. W. Mock and G. A. Parker, The Evolution of Sibling Rivalry, Oxford University Press, Oxford, UK, 1997.

[11] E. Lobato, J. Moreno, S. Merino et al., "Maternal clutch reduction in the pied flycatcher Ficedula hypoleuca: an undescribed clutch size adjustment mechanism," Journal of Avian Biology, vol. 37, no. 6, pp. 637-641, 2006.

[12] C. W. Fox and M. E. Czesak, "Evolutionary ecology of progeny size in arthropods," Annual Review of Entomology, vol. 45, pp. 341-369, 2000.

[13] E. Pukowski, "Ökologische Untersuchungen an Necrophorus F," Zeitschrift für Morphologie und Ökologie der Tiere, vol. 27, no. 3, pp. 518-586, 1933.

[14] A.-K. Eggert and J. K. Müller, "Biparental care and social evolution in burying beetles: lessons from the larder," in The Evolution of Social Behavior in Insects and Arachnids, J. C. Choe and B. J. Crespi, Eds., pp. 216-236, Cambridge University Press, Cambridge, UK, 1997.

[15] M. P. Scott, "The ecology and behavior of burying beetles," Annual Review of Entomology, vol. 43, pp. 595-618, 1998.

[16] J. K. Müller, A.-K. Eggert, and E. Furlkröger, "Clutch size regulation in the burying beetle Nicrophorus vespilloides Herbst (Coleoptera: Silphidae)," Journal of Insect Behavior, vol. 3, no. 2, pp. 265-270, 1990.

[17] S. Suzuki, "Does carrion-burial by Nicrophorus vespilloides (Silphidae: Coleoptera) prevent discovery by other burying beetles?" Entomologial Science, vol. 2, no. 2, pp. 205-208, 1999.
[18] S. T. Trumbo, "Infanticide, sexual selection and task specialization in a biparental burying beetle," Animal Behaviour, vol. 72, no. 5, pp. 1159-1167, 2006.

[19] I. C. Robertson, "Nest intrusions, infanticide, and parental care in the burying beetle, Nicrophorus orbicollis (Coleoptera: Silphidae)," Journal of Zoology, vol. 231, no. 4, pp. 583-593, 1993.

[20] J. Bartlett, "Filial cannibalism in burying beetles," Behavioral Ecology and Sociobiology, vol. 21, no. 3, pp. 179-183, 1987.

[21] D. A. Roff, The Evolution of Life Histories: Theory and Analysis, Chapman and Hall, New York, NY, USA, 1992.

[22] M. J. West-Eberhard, Developmental Plasticity and Evolution, Oxford University Press, Oxford, UK, 2003.

[23] E. Jablonka and M. J. Lamb, Evolution in Four Dimensions: Genetic, Epigenetic, Behavioral, and Symbolic Variation in the History of Life, MIT Press, Cambridge, Mass, USA, 2005.

[24] M. Mesterton-Gibbons and I. C. W. Hardy, "The influence of contests on optimal clutch size: a game-theoretic model," Proceedings of the Royal Society B, vol. 271, no. 1542, pp. 971978, 2004.

[25] G. Blouin-Demers and P. J. Weatherhead, "A novel association between a beetle and a snake: parasitism of Elaphe obsoleta by Nicrophorus pustulatus," Ecoscience, vol. 7, no. 4, pp. 395-397, 2000.

[26] G. Smith, S. T. Trumbo, D. S. Sikes, M. P. Scott, and R. L. Smith, "Host shift by the burying beetle, Nicrophorus pustulatus, a parasitoid of snake eggs," Journal of Evolutionary Biology, vol. 20, no. 6, pp. 2389-2399, 2007.

[27] S. T. Trumbo and G. E. Robinson, "Nutrition, hormones and life history in burying beetles," Journal of Insect Physiology, vol. 50, no. 5, pp. 383-391, 2004.

[28] N. Greenberg, T. Chen, and D. Crews, "Social status, gonadal state, and the adrenal stress response in the lizard, Anolis carolinensis," Hormones and Behavior, vol. 18, no. 1, pp. 1-11, 1984.

[29] H. E. Fox, S. A. White, M. H. F. Kao, and R. D. Fernald, "Stress and dominance in a social fish," Journal of Neuroscience, vol. 17, no. 16, pp. 6463-6469, 1997.

[30] D. H. Abbott, E. B. Keverne, F. B. Bercovitch et al., "Are subordinates always stressed? A comparative analysis of rank differences in cortisol levels among primates," Hormones and Behavior, vol. 43, no. 1, pp. 67-82, 2003.

[31] M. Poisbleau, H. Fritz, N. Guillon, and O. Chastel, "Linear social dominance hierarchy and corticosterone responses in male mallards and pintails," Hormones and Behavior, vol. 47, no. 4, pp. 485-492, 2005.

[32] M. I. McCormick, "Indirect effects of heterospecific interactions on progeny size through maternal stress," Oikos, vol. 118, no. 5, pp. 744-752, 2009.

[33] G. P. Moberg, "How behavioral stress disrupts the endocrine control of reproduction in domestic animals," Journal of Dairy Science, vol. 74, no. 1, pp. 304-311, 1991.

[34] A.-K. Eggert, T. Otte, and J. K. Müller, "Starving the competition: a proximate cause of reproductive skew in burying beetles (Nicrophorus vespilloides)," Proceedings of the Royal Society B, vol. 275, no. 1650, pp. 2521-2528, 2008.

[35] A.-K. Eggert and J. K. Müller, “Timing of oviposition enables dominant female burying beetles to destroy brood-parasitic young," Animal Behaviour, vol. 82, no. 6, pp. 1227-1233, 2011.

[36] J. K. Müller and A.-K. Eggert, "Time-dependent shifts between infanticidal and parental behavior in female burying beetles a 
mechanism of indirect mother-offspring recognition," Behavioral Ecology and Sociobiology, vol. 27, no. 1, pp. 11-16, 1990.

[37] P. T. Smiseth, W. Hwang, S. Steiger, and J. K. Müller, "Adaptive consequences and heritable basis of asynchronous hatching in Nicrophorus vespilloides," Oikos, vol. 117, no. 6, pp. 899-907, 2008. 

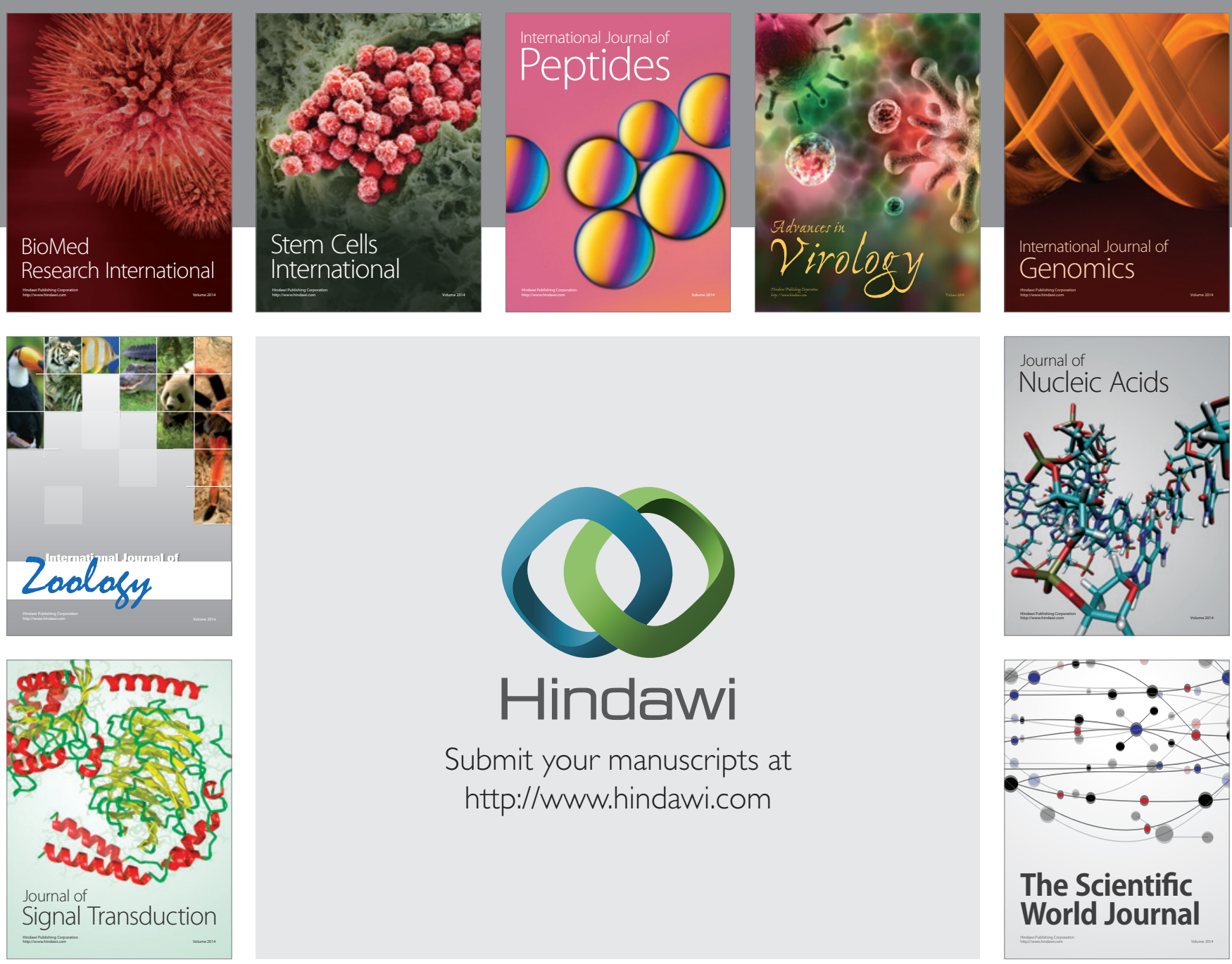

Submit your manuscripts at

http://www.hindawi.com
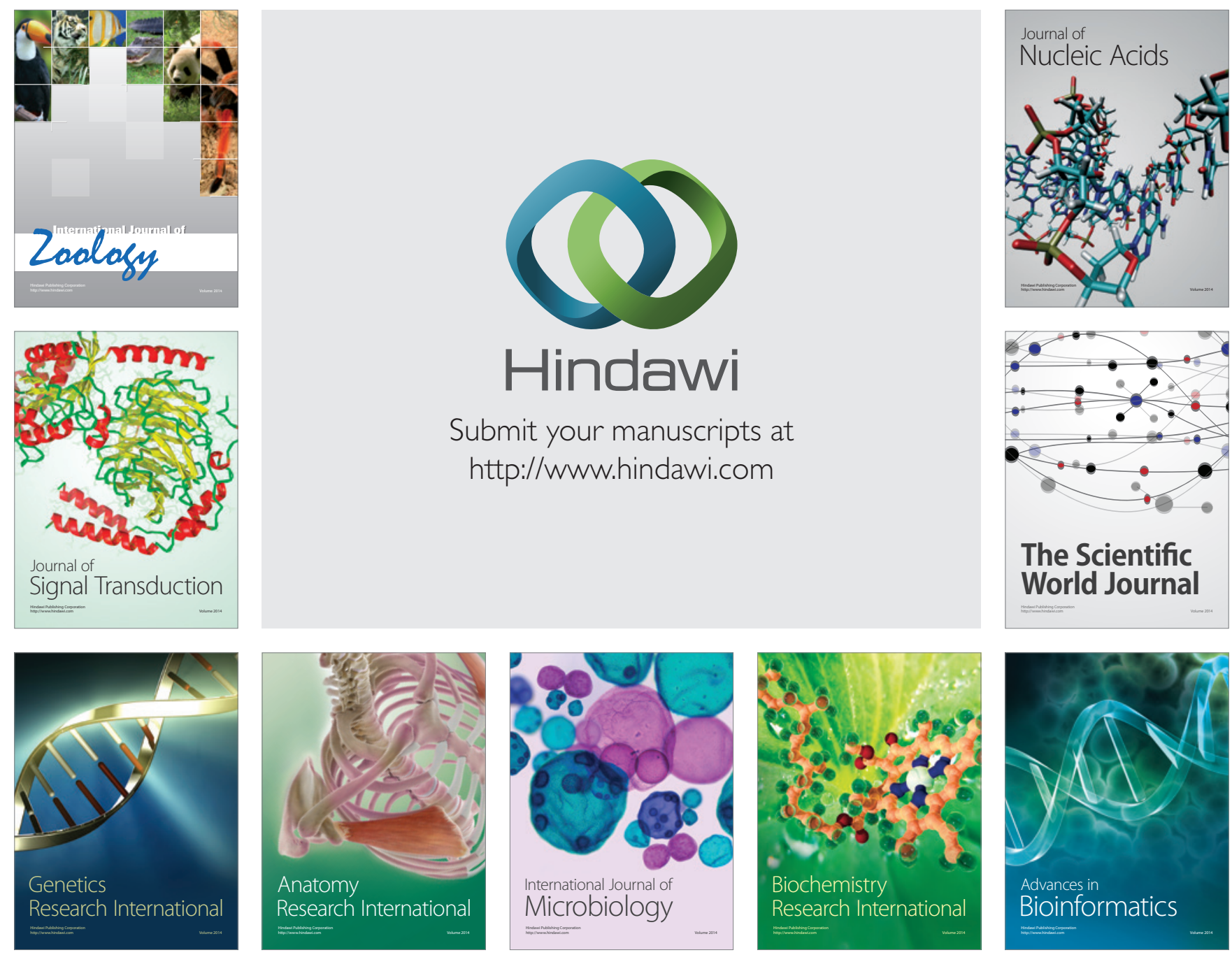

The Scientific World Journal
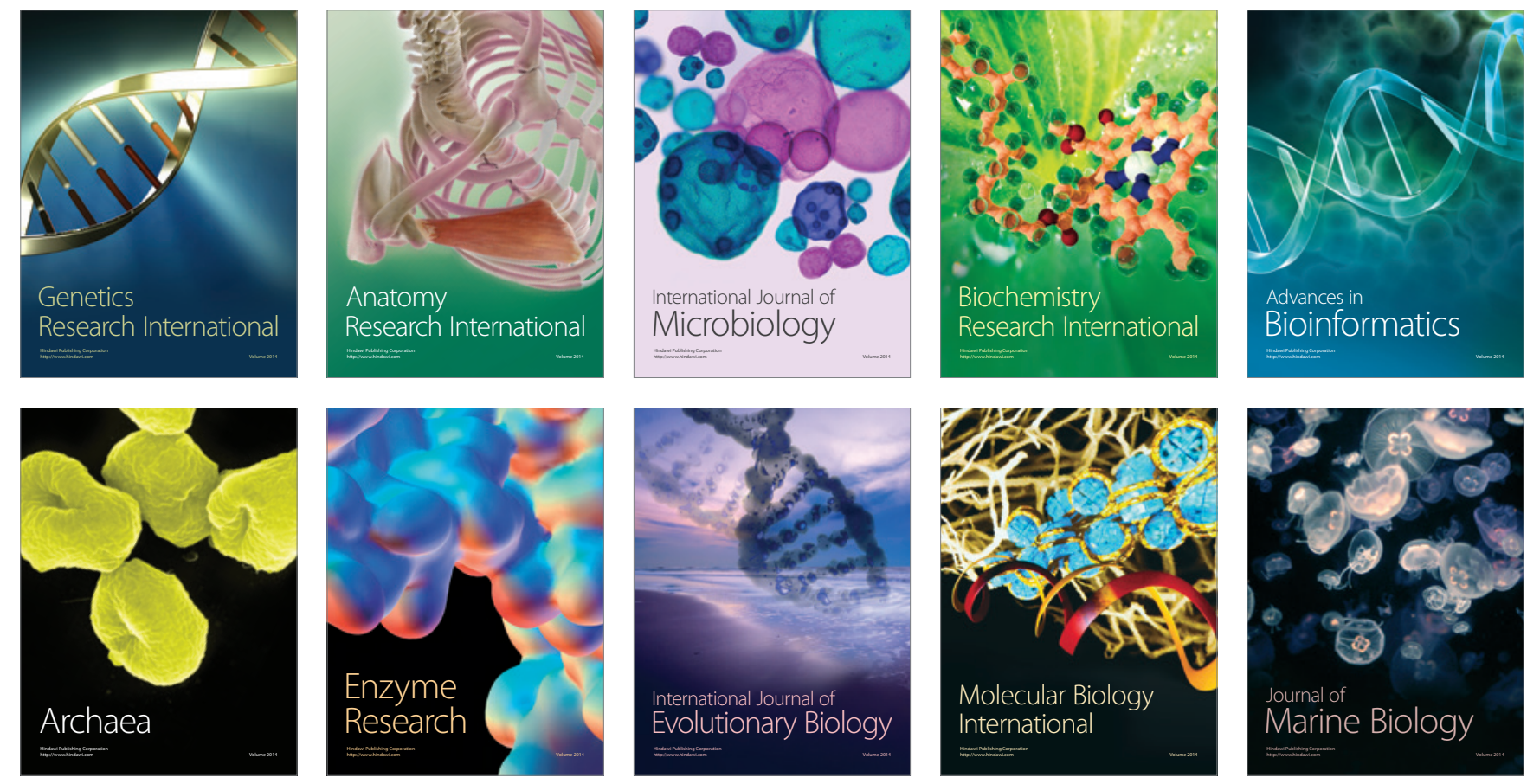